\title{
PESQUISA DE FORMAS EVOLUTIVAS DE PARASITAS CAUSADORES DE ZOONOSES EM TANQUES DE AREIA DE ESCOLAS PÚBLICAS DE EDUCAÇÃO INFANTIL DE ESPÍRITO SANTO DO PINHAL - SP
}

\author{
MENDES, Patrícia Franciscone ${ }^{1}$ \\ CAMARGO, Luciana Bonato de ${ }^{1}$
}

\begin{abstract}
RESUMO: As escolas de ensino infantil comumente apresentam tanques de areia que são utilizados pelas crianças como área de lazer. Nestes locais, cães e gatos muitas vezes têm acesso e eliminam fezes contendo ovos e larvas de parasitas. Entre os parasitas encontrados nestas áreas destacam-se os do gênero Toxocara sp. e Ancylostoma sp., causadores de enfermidades conhecidas como larva migrans visceral e larva migrans cutânea, respectivamente. Este trabalho teve como objetivo pesquisar as formas evolutivas destes parasitas em tanques de areia de 16 escolas públicas de educação infantil de Espírito Santo do Pinhal - SP. Amostras de areia foram coletadas e analisadas quanto à presença de ovos e larvas infectantes empregando-se o Método de Baermann Modificado e o Método de Flutuação com Solução Saturada de Sacarose. Detectou-se a presença de ovos de Toxocara sp. em 14 escolas e larvas do mesmo parasita foram encontradas em 11 escolas. Em relação ao Ancylostoma sp., foram encontrados ovos em 1 escola e em 100\% das escolas analisadas observou-se a presença de larvas do mesmo parasita. Conclui-se que estas áreas de lazer representam importantes focos de transmissão de doenças parasitárias. Entre as medidas preventivas, podem ser consideradas a instalação de cercas e a cobertura dos tanques com lona plástica. A conscientização da população sobre essas parasitoses representa um importante meio de profilaxia para redução e controle destas doenças.
\end{abstract}

Palavras-chave: Toxocara sp.. Larva migrans visceral. Ancylostoma sp.. Larva migrans cutânea.

\section{SURVEY OF EVOLUTIVE TYPES OF ZOONOTIC PARASITES IN SAND DESTINED TO THE RECREATION IN PUBLIC SCHOOLS OF INFANTILE TEACHING OF ESPÍRITO SANTO DO PINHAL - SP}

\begin{abstract}
SUMMARY: Schools of infantile teaching usually have sand used by children as playground. In these places, dogs and cats often have acess and eliminate feces containing parasite eggs and larvae. The most common parasites found in these areas are of the genus Ancylostoma sp. and Toxocara sp. which cause diseases known as visceral larva migrans and cutaneous larva migrans, respectively. This study aimed to investigate the evolutive types of these parasites in sand of 16 public schools of infantile teaching of Espírito Santo do Pinhal - SP. Samples of sand were collected and analyzed for the presence of eggs and larvae using the modified Baermann method and saturated solution of sucrose. The presence of Toxocara sp. eggs were detected in 14 schools and larvae of the same parasite were found in 11 schools. Ancylostoma sp. eggs were detected in just 1 school and $100 \%$ of the schools examined showed the presence of larvae of this parasite. It is concluded that these areas represent important focus of transmission of parasitic diseases. Some preventive measures, can be considered like fences installation and plastic covers for the tanks. The public awareness of parasitic infestation is very important to prevent, reduce and control theses diseases.
\end{abstract}

Keywords: Toxocara sp.. Visceral larva migrans. Ancylostoma sp.. Cutaneous larva migrans.

\footnotetext{
${ }^{1}$ Unipinhal
} 


\section{INTRODUÇÃO}

A maioria das escolas de ensino infantil apresenta tanques de areia em suas áreas de lazer. Locais como esses são muito freqüentados por crianças e podem ser considerados focos de transmissão de várias zoonoses parasitárias, representando um grande risco potencial para as crianças que brincam nesses lugares (NUNES et al., 2000).

Cães e gatos infectados e com acesso a esses locais de recreação contaminam o solo, eliminando até 15.000 ovos de parasitas por grama de fezes, e estes permanecem viáveis por longo período no ambiente expondo a população humana ao risco de infecção e desenvolvimento de doenças (ARAÚJO et al., 1999).

A infecção parasitária é muito freqüente em crianças, cujos hábitos geofágicos e onicofágicos levam-nas a ingerir ovos e oocistos de parasitas presentes no ambiente, e cujo contato direto com a areia as predispõe a penetração ativa percutânea de larvas de helmintos (ACHA, SZYFRES, 1989).

Os hábitos higiênicos mais precários ou a ausência de imunidade à re-infecções também são fatores que tornam as parasitoses mais freqüentes e relevantes em crianças, principalmente com idade entre 0 a 5 anos (UCHÔA et al., 2001).

Pesquisas anteriores relatam que os parasitas mais comumente encontrados nesses locais são os do gênero Toxocara sp e Ancylostoma sp, que são eliminados no ambiente através das fezes de cães e gatos infectados (COSTA-CRUZ, NUNES, BUSO, 1994).

A grande frequiência de ovos e/ou larvas de parasitas, observada em ambientes de recreação infantil como creches, escolas e clubes sugerem que, provavelmente, não são adotadas medidas restritivas rígidas para controle da circulação de animais, principalmente cães e gatos, nesses locais (GUIMARÃES et al., 2005).

A toxocaríase é uma zoonose de distribuição mundial e considerada a helmintíase mais prevalente em países industrializados, entretanto é pouco reconhecida como problema de saúde pública e subestimada principalmente em locais favoráveis ao seu desenvolvimento (ALDERETE et al., 2003).

O Toxocara canis e o Toxocara cati são nematódeos da família Ascaridae que parasitam, respectivamente, cães e gatos. Nestes animais, considerados hospedeiros definitivos, as fêmeas adultas presentes no intestino delgado são capazes de produzir ovos que são eliminados juntamente com as fezes dos animais, tornando-se infectantes em duas a cinco semanas, sob condições ambientais de temperatura e umidade adequadas (SCHANTZ, 1989).

Uma vez presentes no solo, os ovos larvados podem ser ingeridos pelos seres humanos. Após a ingestão, as larvas eclodem no intestino delgado, atingem a circulação sanguínea pela via hepática, migrando para diversos órgãos (Figura 1), podendo ocasionar a síndrome larva migrans visceral, ou provocar danos ao sistema oftálmico, conhecidos como síndrome de larva migrans ocular (Figuras 2 e 3) (DESPOMMIER, 2003). 
Figura 1. Ciclo biológico do Toxocara sp. Fonte: Parasidiário, 2011.

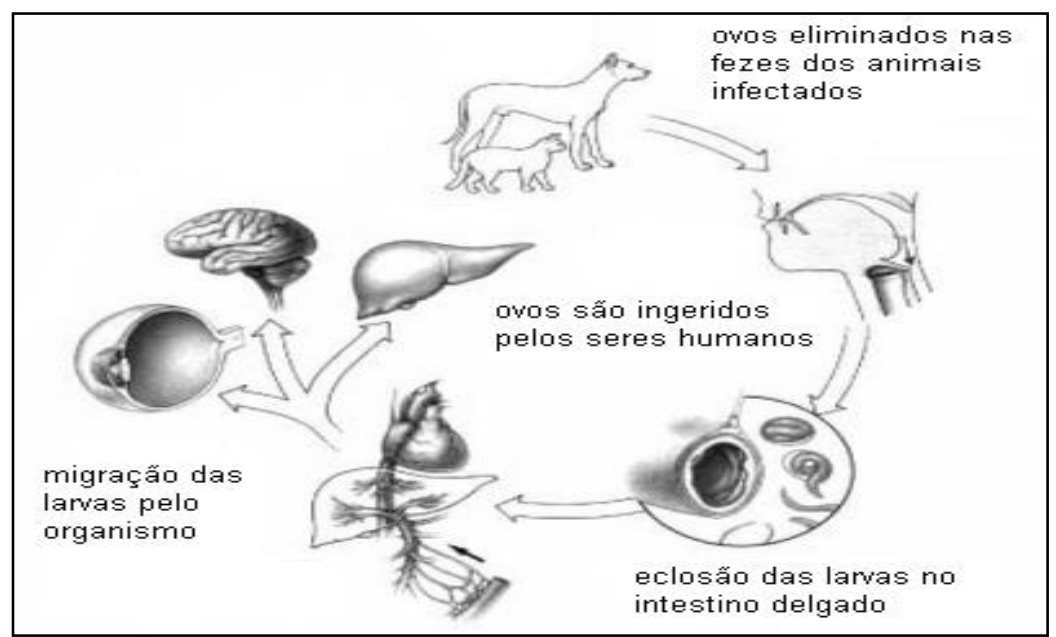

Figura 2. Lesão localizada em globo ocular esquerdo, ocasionada pela síndrome larva migrans ocular.

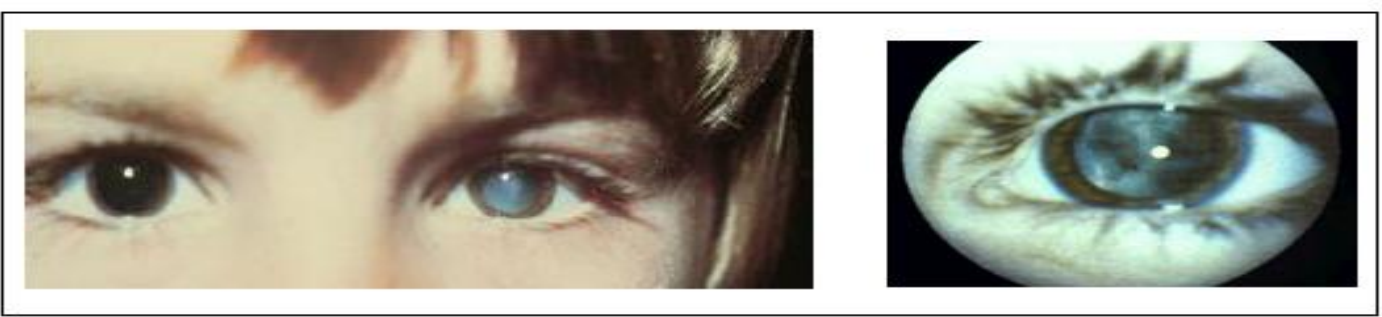

Fonte: Policlínica Veterinária de Cotia, 2011.

As manifestações causadas pela infecção pelo Toxacara sp. são ainda mais graves em crianças com 0 a 5 anos de idade, desnutridas ou com baixa imunidade, podendo nestas condições causar sintomas polimorfos como acessos asmáticos, febre alta, anorexia, artralgias, mialgias, náuseas, vômitos, hepatomegalia, linfadenopatia, urticária e edema angioneurótico (BRITES NETO, 1997).

O diagnóstico da toxocaríase baseia-se na realização de exames clínicos e laboratoriais através do método de ELISA (Enzyme Linked ImmunonoSorbent Assay), utilizando-se imunoglobulinas antiToxocara sp., cujos resultados elevados indicam doença recente e, os mais baixos, infecção leve ou em resolução. Os valores obtidos devem ser associados aos dados epidemiológicos relacionados ao contato do indivíduo com animais ou exposição a locais passíveis de contaminação por ovos de Toxocara sp. (CARVALHO, ROCHA, 2011).

A associação entre toxocaríase e a presença de sintomas clínicos diversos e potencialmente graves nas crianças reforça a importância de se considerar esta doença como um importante problema de saúde pública (YAMASAKI et al., 2000).

A ancilostomose, assim como a toxocaríase, é uma doença muito comum em vários estados do Brasil. O Ancylostoma caninum, o Ancylostoma braziliensis e o Ancylostoma tubaeforme, são nematódeos da família Ancylostomidae que parasitam cães e gatos, os animais infectados são capazes de eliminar diariamente no ambiente através das fezes milhares de ovos destes parasitas (FORTES, 1997).

A ancilostomose ocorre mais frequentemente em praias e em terrenos arenosos onde animais infectados com ancilostomídeos poluem o meio com suas fezes. Nesses lugares a natureza do solo, o calor e a umidade elevada favorecem o desenvolvimento das larvas até o estágio infectante (CHIEFFI 
et al., 2010) (Figura 4). Pesquisas demonstram que as zonas banhadas diretamente pelo mar não oferecem risco, pois o teor salino do terreno impede a sobrevivência dos ovos e das larvas de ancilostomídeos (REY, 2001).

Figura 4. Ciclo biológico do Ancylostoma sp. Fonte: Instituto de Medicina Tropical de São Paulo, 2011.

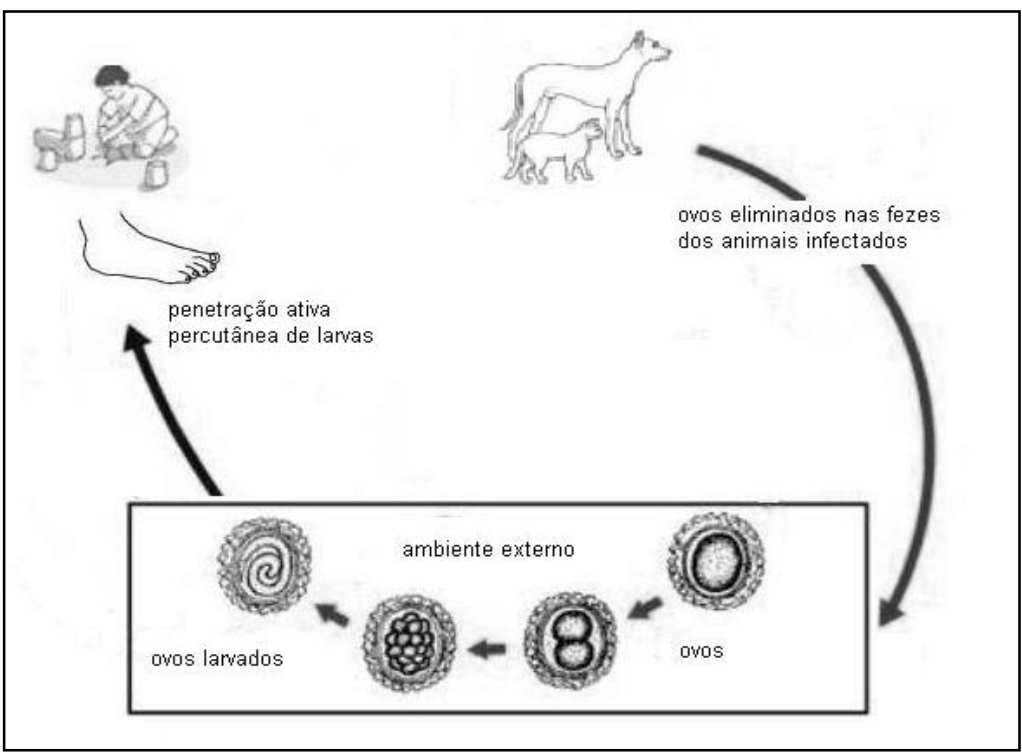

Uma vez no meio exterior, em condições ideais de temperatura, umidade e oxigenação, esses ovos embrionam e eclodem, liberando larvas. A infecção nos animais pode ser por via oral (mais comum) ou cutânea (FORTES, 1997).

No homem a infecção é considerada acidental, pois a larva ao penetrar através da pele não consegue encontrar seu caminho, por isso permanece entre a epiderme e a derme, deixando um rastro sinuoso conhecido popularmente por "bicho-geográfico" (Figura 5 e 6). Por não conseguir realizar seu ciclo de vida normal morre depois de semanas ou meses (URQHART, ARMOUR, DUNCAN, 1996).

No local da penetração, em pessoas mais sensibilizadas, podem surgir pontos eritematosos ou pápulas acompanhados de prurido. Destes pontos partem os túneis que desenham um trajeto irregular e deixam para trás um cordão eritematoso, saliente e pruriginoso, às vezes recoberto por vesículas. $\mathrm{O}$ prurido intenso provocado por essas lesões pode fazer com que o paciente ao se coçar ocasione escoriações na pele que podem evoluir para infecções microbianas secundárias (REY, 2001).

Figura 5. Lesões localizadas em membro inferior, ocasionadas pelo deslocamento subcutâneo de larva de Ancylostoma sp. Fonte: Policlínica Veterinária de Cotia, 2011.

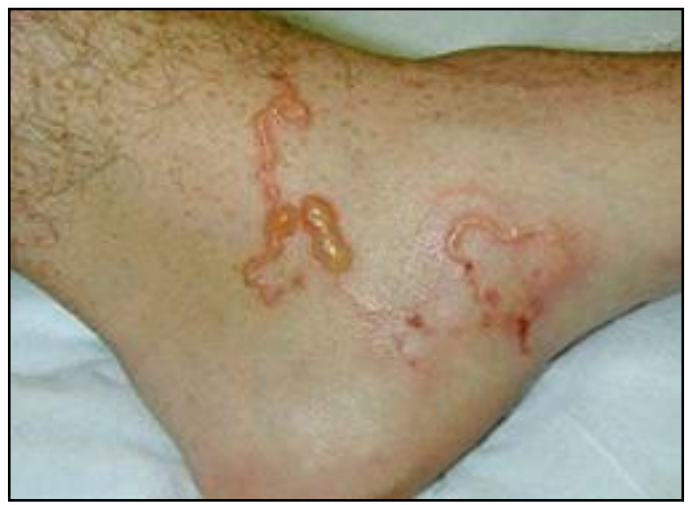


Figura 6. Lesões localizadas em região plantar, ocasionadas pelo deslocamento subcutâneo de larva de Ancylostoma sp. Fonte: Policlínica Veterinária de Cotia, 2011.

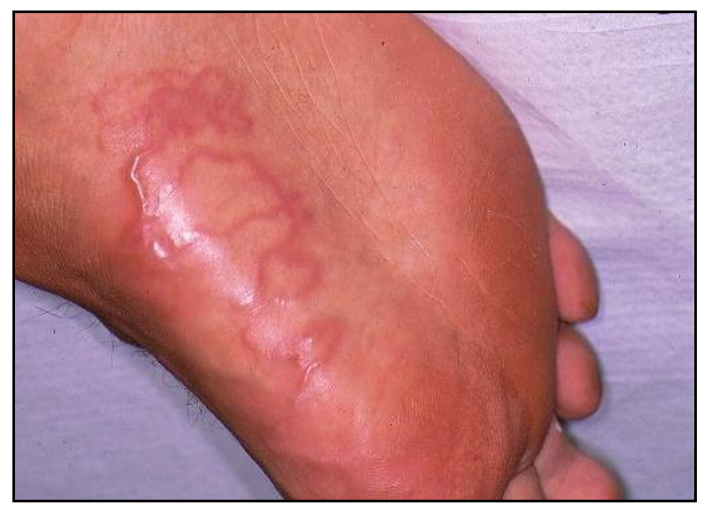

A poluição fecal do meio, pelos animais não-tratados, não-curados ou reinfectados, continua a acrescentar novas quantidades de ovos do parasita no solo, promovendo assim, o aumento do número de larvas infectantes. Nessas condições, a transmissão da ancilostomíase permanece ativa e assegura a reinfecção (REY, 2001).

A ancilostomose pode ser diagnosticada através da realização de exames clínicos, devido ao prurido característico desta doença e exames laboratoriais, utilizando-se os métodos de sedimentação espontânea como o método de Willis, Lutz e Faust ou contagem de ovos pelo método de Kato-Katz (BRASIL, 2010).

Uma quantidade significativa de proprietários de cães e gatos não se preocupam de maneira ideal com a saúde de seus animais, visando garantir, conseqüentemente, a própria saúde, visto que as doenças parasitárias descritas são zoonoses (ROCHA et al., 2008).

Nesse contexto, este trabalho tem como objetivo pesquisar a presença de formas evolutivas de parasitas causadores de zoonoses em tanques de areias destinados ao lazer nas escolas públicas municipais de educação infantil da cidade de Espírito Santo do Pinhal - SP e em seguida orientar sobre as medidas de controle e prevenção para cada escola de acordo com a necessidade.

\section{MATERIAL E MÉTODOS}

Espírito Santo do Pinhal é um município do estado de São Paulo, localizado a uma latitude de $22^{\circ} 11^{\prime 2} 27^{\prime \prime}$ sul e a uma longitude $46^{\circ} 44^{\prime} 27^{\prime \prime}$ oeste, estando a uma altitude de 870 metros. Possui uma área de 390,413km² estimando-se cerca de 41.919 habitantes (IBGE, 2010).

Este trabalho foi realizado em 16 escolas públicas municipais de educação infantil, em Espírito Santo do Pinhal, SP. As amostras foram coletadas semanalmente, no período de Maio a Dezembro de 2010 e processadas no Laboratório de Doenças Parasitárias, do Hospital Veterinário do Curso de Medicina Veterinária do Centro Regional Universitário de Espírito Santo do Pinhal (UNIPINHAL).

Em cada escola foi aplicado um questionário aos seus dirigentes e professores, buscando informações relacionadas à faixa etária das crianças que freqüentam os tanques de areia, acesso de animais aos tanques, características físicas da areia e cuidados com a areia dos tanques. 
As coletas foram realizadas com auxílio de um tubo de PVC (policloreto de vinila), de 3,70 $\mathrm{cm}$ de diâmetro, à aproximadamente $7 \mathrm{~cm}$ de profundidade, no período compreendido entre 7:00 horas e 10:00 horas, sendo que de cada tanque de areia foram coletadas 5 amostras. Considerando-se os tanques das 16 escolas analisadas, obteve-se um total de 95 amostras, pois 3 escolas apresentavam 2 tanques de areia.

Para análise parasitológica foram utilizados $100 \mathrm{~g}$ de areia de 5 locais diferentes de cada tanque, as amostras foram identificadas e armazenadas em sacos plásticos estéreis sob refrigeração $\left(10^{\circ} \mathrm{C}\right)$ até serem processadas.

Após a coleta as amostras foram enviadas ao Laboratório de Doenças Parasitárias. Cada amostra foi analisada separadamente utilizando-se o Método de Baermann Modificado (MORAES, 1948) para a pesquisa de larvas, e através do Método de Flutuação com Solução Saturada de Sacarose para a pesquisa de ovos e oocistos de nematóides e protozoários (HOFFMAN, 1987).

Para a realização de tais métodos foram utilizados os seguintes materiais: cálice de Hoffman, pipeta, gaze, copos descartáveis, lâminas, lamínulas, vidro de relógio, peneira, água destilada, açúcar, lugol P.A., tubo cônico para centrifugação, centrífuga, balança analítica, microscópio óptico e lupa.

Primeiramente realizou-se a pesquisa de larvas infectantes utilizando-se o Método de Baermann Modificado, o qual foi realizado no mesmo dia da coleta, visto que as larvas podem se tornar inviáveis em pouco tempo fora do ambiente.

O Método de Baermann fundamenta-se no hidrotropismo e termotropismo positivo das larvas, e para a sua realização, inicialmente foi feito o aquecimento de água destilada à temperatura de $45^{\circ} \mathrm{C}$, que em seguida foi colocada em cálices de sedimentação de Hoffman, os quais foram preenchidos até a borda. Posteriormente, $30 \mathrm{~g}$ de areia de cada amostra foram pesadas, em copos descartáveis numerados de acordo com o número da amostra, utilizando-se balança analítica. As amostras foram então depositadas em peneira forrada com gaze, e colocadas sobre os cálices de Hoffman para que a água pudesse entrar em contato com a areia, permanecendo assim em repouso por 3 horas. Após esse período as peneiras foram retiradas e o sobrenadante dos cálices descartados. Com o auxílio de uma pipeta, o material sedimentado no fundo do cálice foi retirado, colocado em vidros de relógio e examinado em lupa e microscópio óptico, usando-se os aumentos de 10 e 40 vezes.

O Método de Flutuação com Solução Saturada de Sacarose também foi realizado no dia da coleta das amostras, utilizando-se $10 \mathrm{~g}$ de areia que foi lavada por agitação e tamizada. O líquido resultante da lavagem foi submetido à centrifugação e o sobrenadante foi desprezado. Ao sedimento adicionou-se solução saturada de sacarose que foi homogeneizada e em seguida, completou-se o frasco com está solução até a borda para que ocorresse a formação do menisco invertido. Após o período de 10 minutos, a lâmina colocada tocando a superfície do menisco foi invertida bruscamente para evitar a queda do material em suspensão. Com o auxílio da pipeta, colocou-se uma gota de lugol P.A. sobre a lâmina. A lâmina foi coberta com lamínula e examinada ao microscópio óptico, usando-se os aumentos de 10 e 40 vezes.

\section{RESULTADOS E DISCUSSÃO}

Os ovos e parasitas detectados foram analisados microscopicamente e, com auxílio de lupa, identificados e classificados segundo o formato e aparência (Figuras 7, 8, 9 e 10). 
Figura 7. Fotomicrografia, objetiva 10X. Ovo de Ancylostoma sp., formato ovalado, constituído por duas membranas. No interior nota-se a presença de massa germinativa formada por blastômeros (seta). Fonte: Arquivo pessoal.

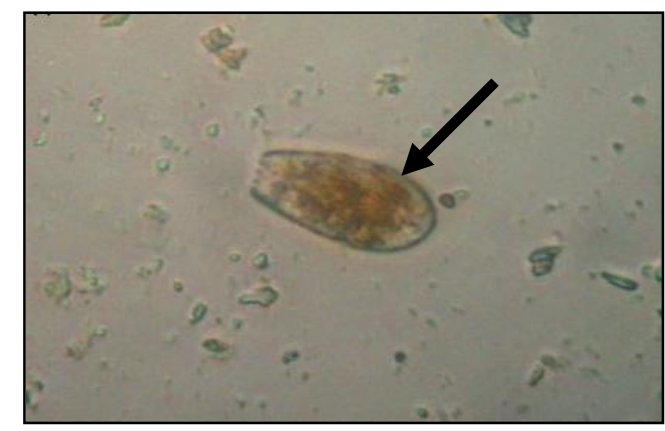

Figura 8. Fotomicrografia, objetiva 10X. Larva de Ancylostoma sp. Observa-se a cauda apresentando terminação reta e fina (seta). Fonte: Arquivo pessoal.

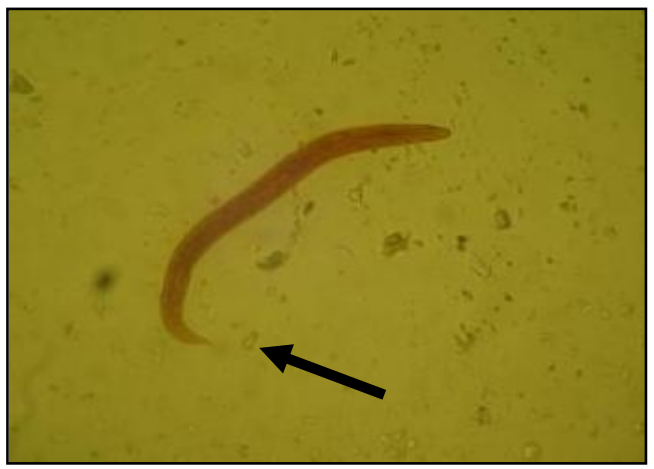

Figura 9. Fotomicrografia, objetiva 10X. Ovo de Toxocara sp., formato circular, constituído por casca espessa e com rugosidades (seta). O embrião preenche todo o conteúdo do ovo. Fonte: Arquivo pessoal.

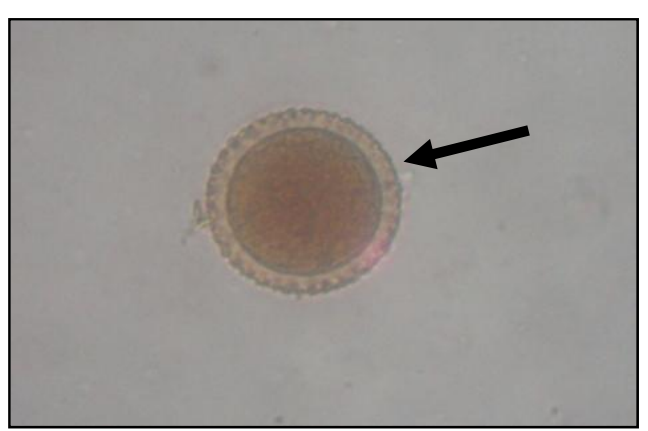

Figura 10. Fotomicrografia, objetiva 40X. Larva de Toxocara sp. Observa-se o formato cilíndrico e na porção cefálica evidencia-se a fenda labial (seta). Fonte: Arquivo pessoal.

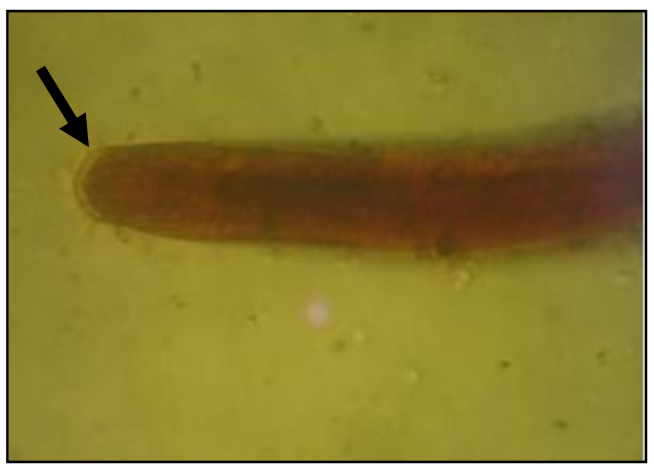


Foram detectados ovos de Toxocara sp. em 14 (87,5\%) e larvas do mesmo parasita em 11 $(68,7 \%)$ das escolas analisadas.

Detectou-se também ovos de Ancylostoma sp. em 1 (6,25\%) e larvas do mesmo parasita foram encontradas em todas (100\%) as escolas analisadas (Figura 11).

Figura 11. Porcentagem de formas evolutivas de parasitas encontrados nos tanques de areia em relação ao número de escolas visitadas. Fonte: Arquivo pessoal.

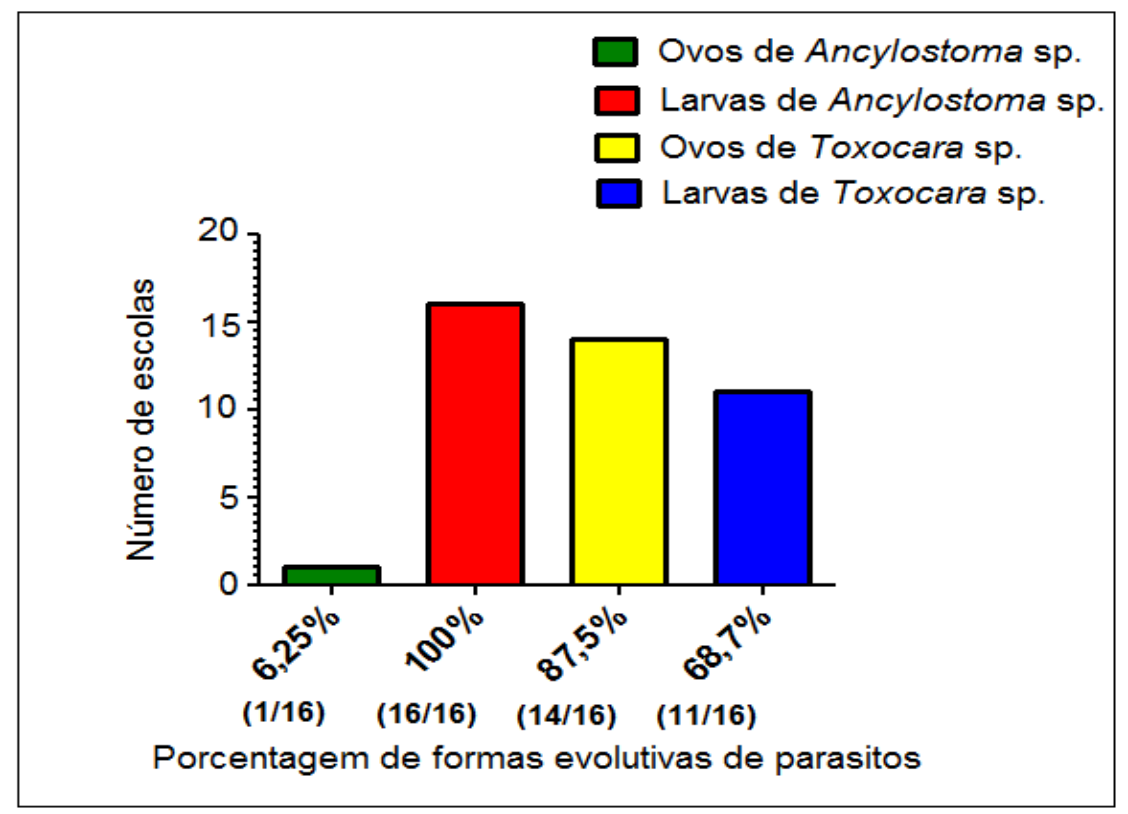

O resultado observado nesta pesquisa é superior ao publicado por NUNES et al. (2000) que ao analisarem amostras de areia procedentes de áreas de recreação infantil de 28 escolas municipais de ensino infantil (EMEI) de Araçatuba - SP, detectaram presença de larvas de Ancylostoma sp. em $46,4 \%$ (13/28) das escolas visitadas e ovos em 0,56\% (3/535) das amostras, todas provenientes de uma mesma escola na qual também se observou a presença de larvas do parasita, porém, relataram que não foi observada a presença de ovos de Toxocara sp. em nenhuma das amostras analisadas.

Comparativamente, os resultados obtidos por GUIMARÃES et al. (2005), também foram inferiores aos observados nesta pesquisa. No referido experimento foram avaliadas amostras de 18 escolas/creches de Lavras - MG, onde detectou-se que o percentual de contaminação ambiental nesses locais foi de 55,5\%, considerando-se o número total de amostras com presença de diferentes formas parasitárias. Quanto aos dados referentes à presença de Ancylsotoma sp. em escolas/creches, observouse percentual de $22,2 \%$ de contaminação referentes a ovos e larvas desse nemátodeo. Ovos de Toxocara sp. não foram encontrados nesses ambientes.

Com base no questionário aplicado nas visitas às instituições de ensino, verificou-se que as escolas públicas municipais de educação infantil trabalhavam com crianças de faixa etária variável entre 4 meses a 6 anos de idade, sendo que, particularmente, uma entidade visitada, responsável por dar assistência a pessoas portadoras de necessidades especiais, trabalhava com crianças, jovens e adultos, variando entre 0 a 69 anos de idade (Figura 12). 
Figura 12. Relação entre faixa etária dos alunos que utilizam os tanques de areia para recreação e a presença de ovos e larvas de Ancylostoma sp e Toxocara sp. (\%). Fonte: Arquivo pessoal.

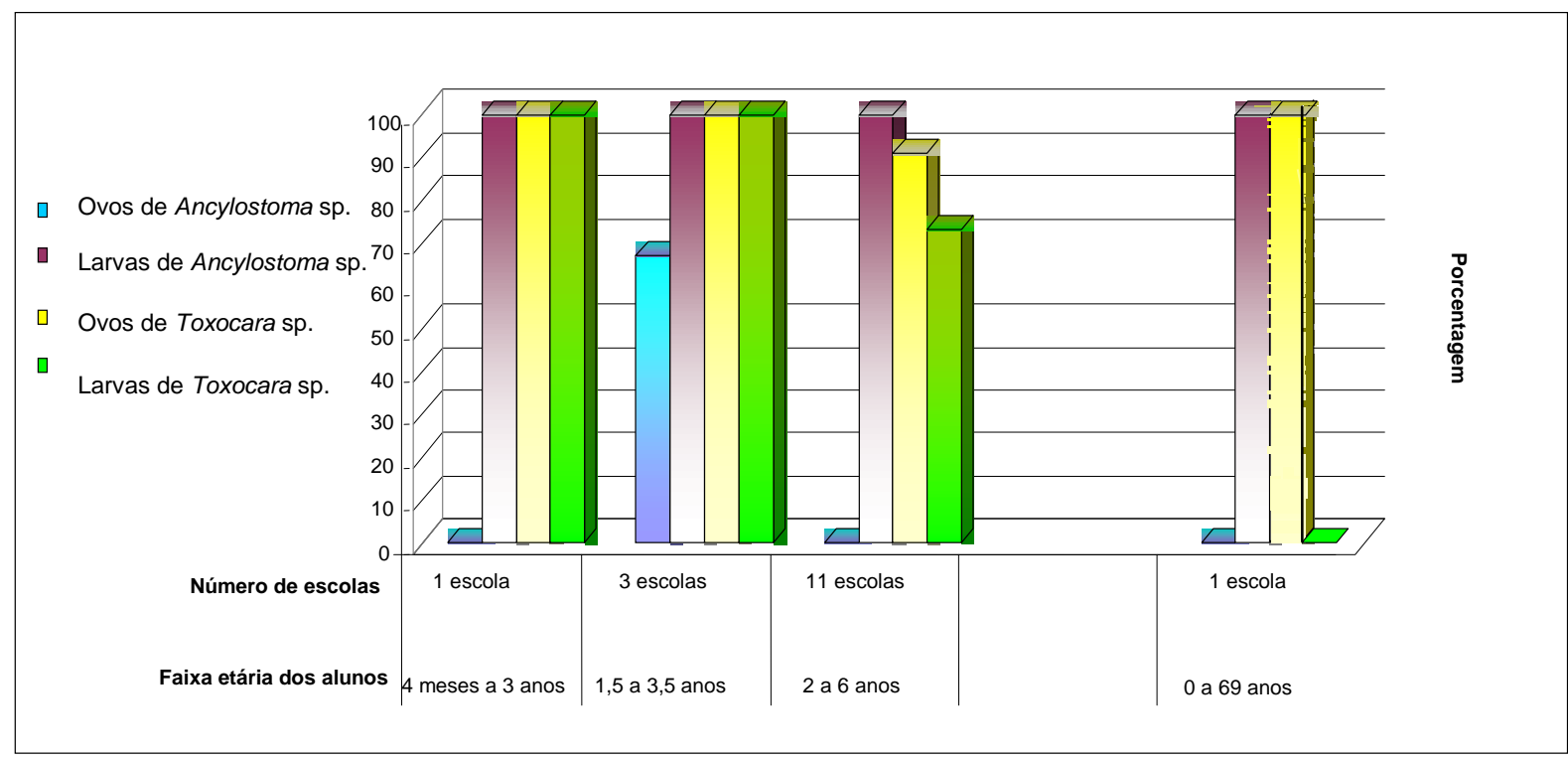

No experimento realizado por CAMARGO et al. (2003), no período de Setembro a Outubro, objetivando investigar a ocorrência de agentes causais de larva migrans em areias destinadas à recreação em escolas municipais de ensino infantil situadas na área urbana de Espírito Santo do Pinhal - SP, foram detectadas larvas de Ancylostoma sp. em 10 (76,9\%) das 13 escolas analisadas e ovos de Toxocara sp foram encontrados em somente uma escola (1,3\%). Os dados obtidos nesse experimento realizado a 8 anos atrás são inferiores em relação aos obtidos nesta pesquisa. Isso sugere que as condições higiênico-sanitárias das escolas ainda apresentam-se deficientes e melhorias são necessárias como medidas preventivas na transmissão de zoonoses.

A influência de fatores ambientais, como a umidade e a temperatura média, podem justificar a menor prevalência de parasitas observada por CAMARGO et al. (2003) quando comparada ao presente estudo. No período em que foi realizada a pesquisa destes autores, é característico na região, a ocorrência de temperaturas elevadas associadas à baixa umidade relativa do ar, o que poderia acarretar a dessecação das formas evolutivas parasitárias no solo.

Outro fator ambiental a ser considerado diz respeito à incidência de luz solar sobre os tanques de areia, comparando-se a presença de parasitas em áreas sombreadas ou não sombreadas observou-se que os tanques sombreados apresentaram maiores percentuais de larvas de Ancylostoma sp. e ovos de Toxocara sp. (Figura 13). Segundo SOTOMAIOR et al. (2009) o sombreamento é um fator importante, pois além de preservar um microambiente de maior umidade, propício para o desenvolvimento dos parasitas, impede a ação dos raios ultra-violeta do sol que podem eliminar os parasitas. 
Figura 13. Relação entre os tanques de areia sombreados e não sombreados e a presença de ovos e larvas de Ancylostoma sp e Toxocara sp. (\%). Fonte: Arquivo pessoal.

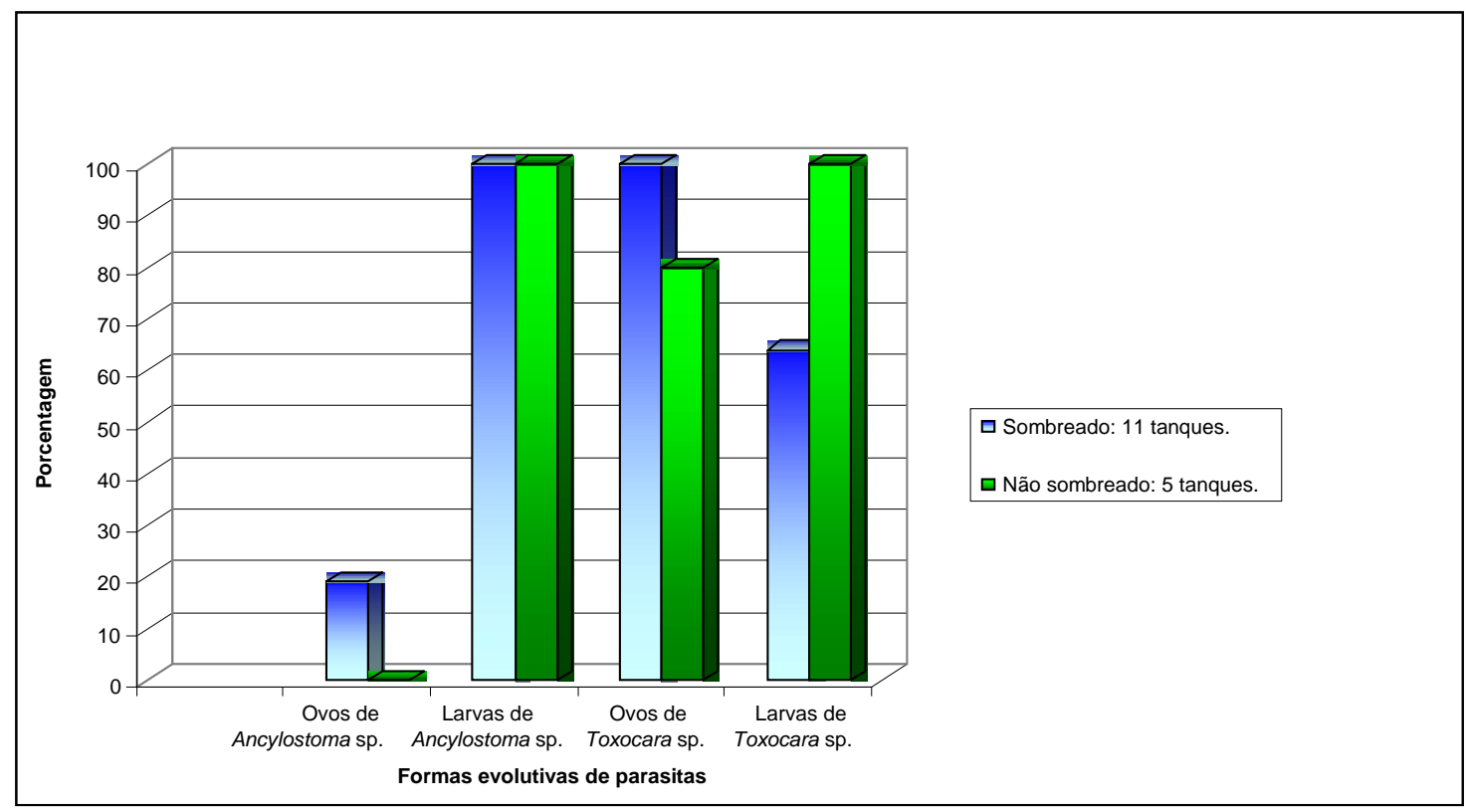

Considerando as características físicas da areia dos tanques (Figura 14), observou-se que aqueles que apresentavam areia úmida registraram maiores percentuais de ovos de Toxocara sp. e larvas de ambos os gêneros de parasitas, concordando mais uma vez com SOTOMAIOR et al. (2009) que afirma que a umidade favorece o desenvolvimento das formas evolutivas parasitárias.

Figura 14. Relação entre as características físicas da areia dos tanques e a presença de ovos e larvas de Ancylostoma sp e Toxocara sp. (\%). Fonte: Arquivo pessoal.

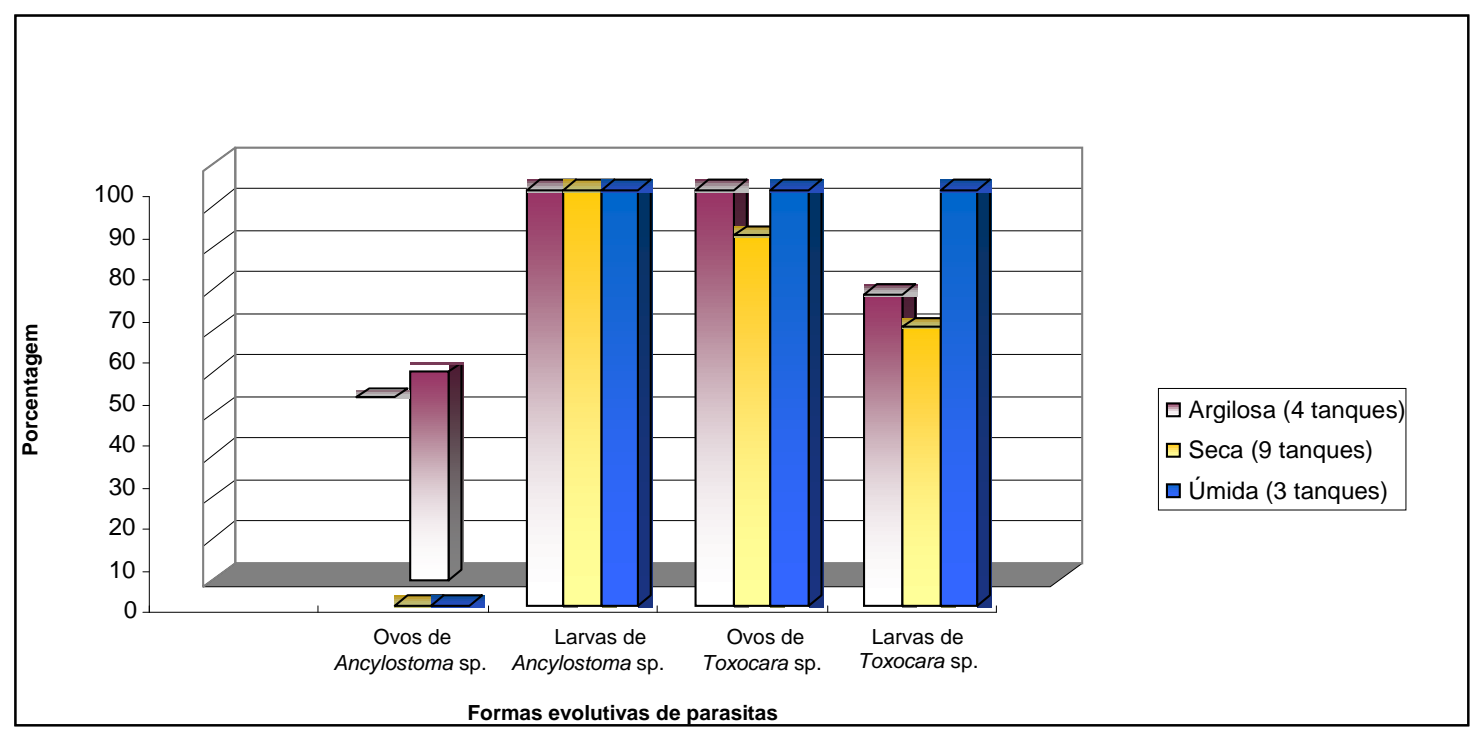

No ciclo de vida de ambos os gêneros de parasitas estudados neste trabalho, a eliminação de ovos ocorre através das fezes de animais infectados. Na maioria dos tanques analisados não foi detectada visualmente a presença de fezes sobre a areia, mesmo assim, observa-se que nesses 
ambientes havia um aumento do percentual de ovos e larvas de parasitas (Figura 15). Este resultado pode ser explicado devido ao fato de que todos os tanques das escolas visitadas não possuíam barreiras físicas que impedissem o acesso de animais a esses locais, considera-se também, que algumas escolas adotam como medida de limpeza dos tanques durante o período matutino, a varredura e a remoção de fezes de animais, o que poderia ter dificultado a constatação da presença de fezes nos tanques.

Figura 15. Relação entre a presença de fezes de animais nos tanques de areia e a detecção de ovos e larvas de Ancylostoma sp e Toxocara sp. (\%). Fonte: Arquivo pessoal.

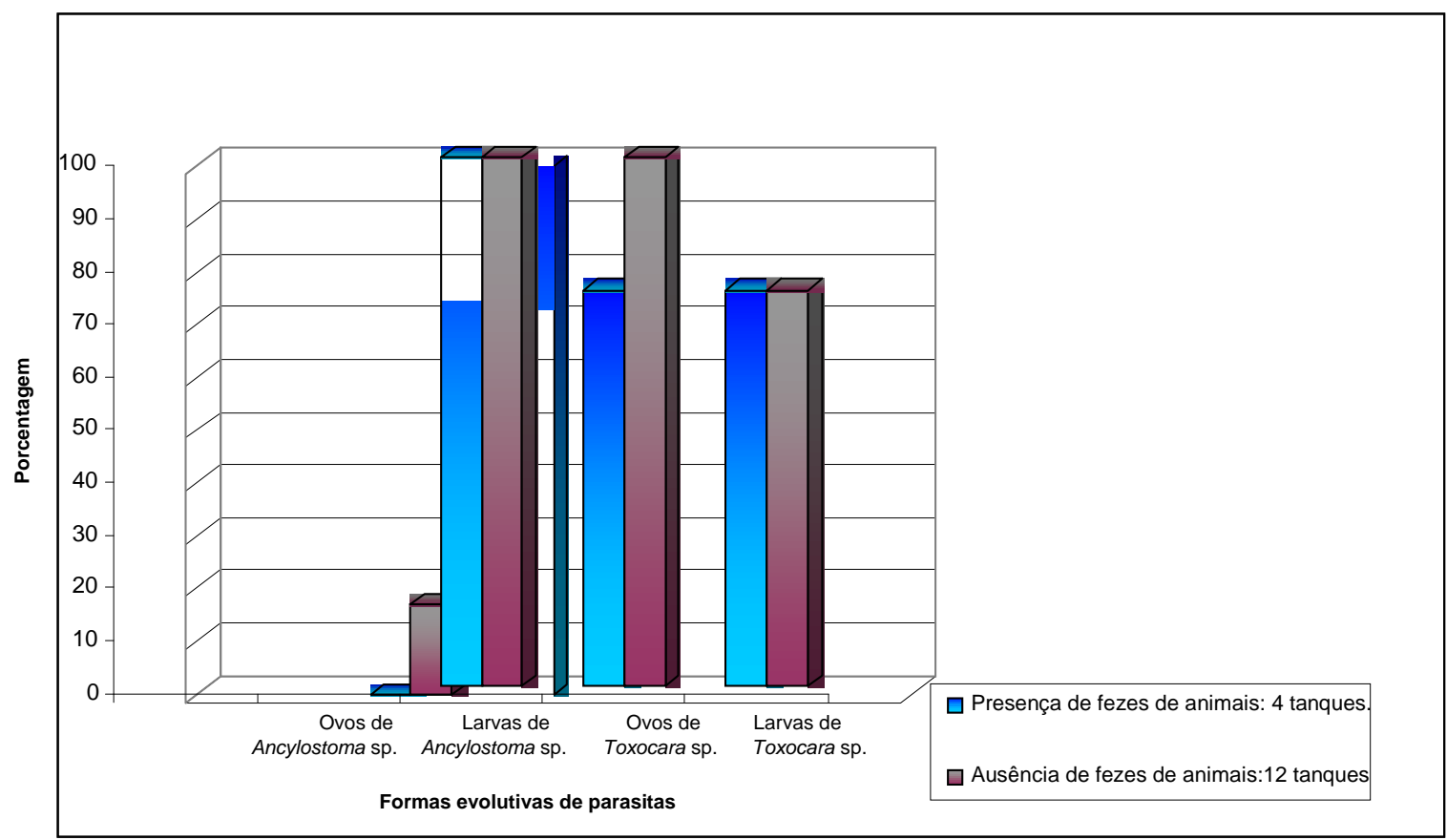

Em relação ao procedimento de manutenção da areia dos tanques (Figura 16), verificou-se que as escolas podem trocar totalmente a areia ( 2 escolas), optar pela permanência da areia ( 3 escolas), ou periodicamente reabastecer os tanques com areia provenientes de outros locais (11 tanques).

Nos tanques em que a areia não era trocada, houve um aumento dos percentuais da presença de parasitas, isso estaria relacionado a constaste manutenção dos ciclos parasitários no ambiente.

Nos tanques submetidos à troca total da areia, os percentuais de presença de formas evolutivas de parasitas foram elevados, provavelmente decorrente da contaminação da areia já no local de origem, contribuindo para introdução dos parasitas nos tanques.

Os tanques submetidos ao reabastecimento de areia apresentaram menores percentuais da presença de parasitas, isso indica que este procedimento pode estar contribuindo para promover a redução da concentração de ovos e larvas nestes locais. 
Figura 16. Relação entre a troca de areia dos tanques e a detecção de ovos e larvas de Ancylostoma sp e Toxocara sp. (\%). Fonte: Arquivo pessoal.

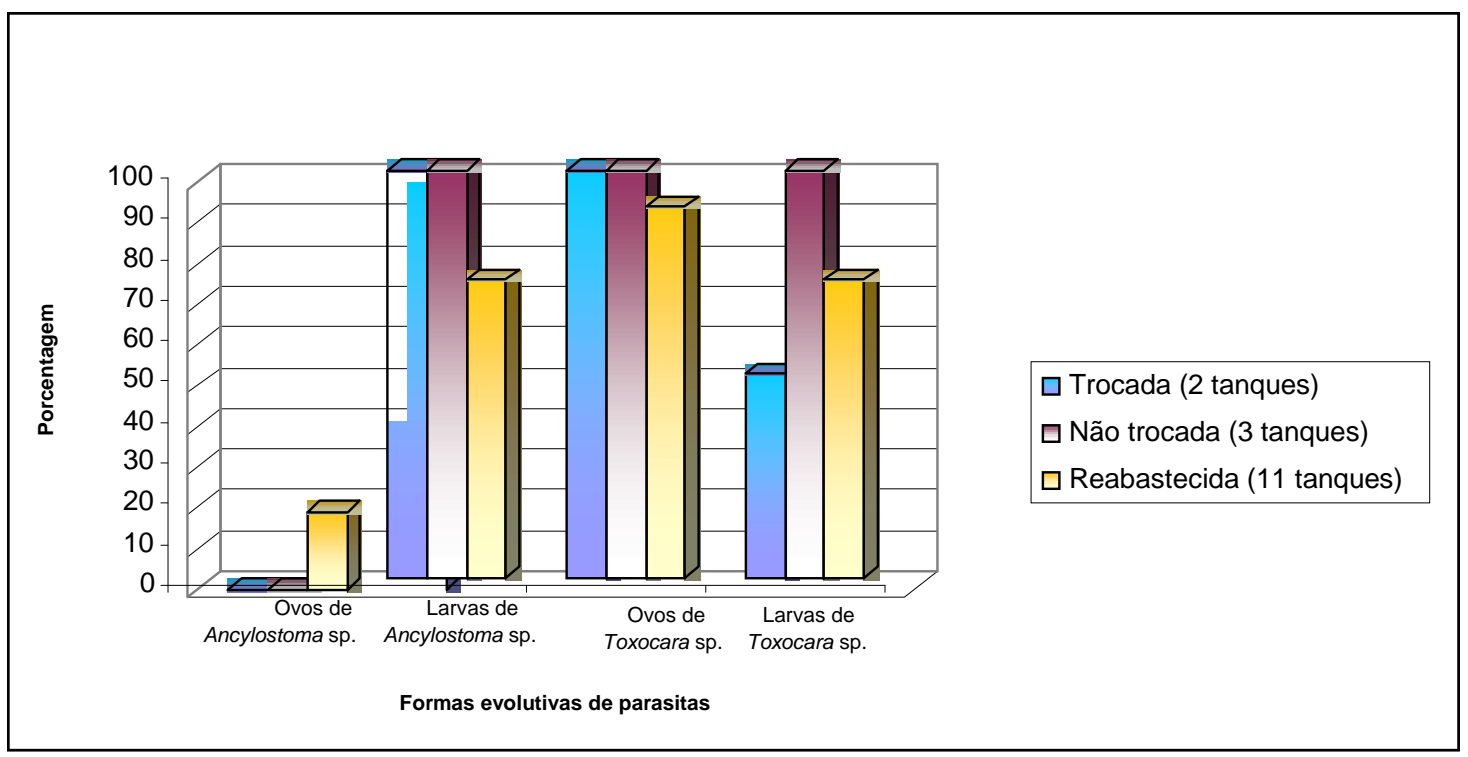

\section{CONSIDERAÇÕES FINAIS}

As escolas e entidades visitadas possuíam tanques de areia destinados ao lazer infantil sem barreiras físicas que impedissem o acesso de animais. Salienta-se que durante as coletas foram observadas fezes de animais nos tanques de areia de algumas escolas. Somente uma das escolas analisadas, adotava um tipo de medida com o objetivo de impedir o acesso de gatos aos tanques de areia durante o período da noite, para isso, todas as tardes, os tanques de areia eram cobertos por uma lona de plástico com a finalidade de proteger a areia da contaminação fecal, visto que o local apresentava uma grande população de gatos errantes, animais que têm o hábito de evacuar na areia e depois cobrir as fezes.

Quanto aos cuidados envolvendo a areia presente nos tanques destinados a recreação infantil, observou-se que na maioria das escolas visitadas a areia não é trocada, os tanques somente são reabastecidos anualmente ou mensalmente, acrescentando-se mais areia aos mesmos. Em algumas escolas o reabastecimento dos tanques não era realizado, permanecendo a mesma areia nos tanques durante anos. Em uma das escolas visitadas, a mesma que recobria os tanques com lona de plástico todas as noites, como medida higiênica do local, adotava-se também a passagem do fogareiro a cada 10 dias sobre os tanques de areia, observou-se, de fato, que essas medidas implantadas contribuíram para redução dos índices de presença de ovos e larvas de parasitas nesse local. Em algumas escolas, durante o período da manhã, a varredura dos tanques era realizada a fim de promover a limpeza da areia.

Avaliou-se também no questionário aplicado o número de tanques apresentado por cada escola, as localizações dos mesmos (local sombreado ou não) e as características físicas da areia analisada, sendo estes fatores consideráveis na determinação da presença e na viabilidade de sobrevivência dos parasitas nestes locais.

Verificamos nesse trabalho com os resultados obtidos que as áreas de lazer das escolas representam importantes focos de transmissão de doenças parasitárias, apresentando potencial de risco para a saúde pública, portanto, a implantação de medidas profiláticas é necessária com a finalidade de reduzir e controlar a disseminação de parasitoses. 
Primordialmente, com a finalidade de evitar à contaminação dos solos arenosos dos espaços destinados a recreação infantil em escolas, recomenda-se a instalação de cercas teladas que impeçam completamente o acesso dos animais a esses locais. Durante a noite recomenda-se realizar a cobertura das caixas de areia com lona plástica adequada e resistente, devido ao fato dos felinos conseguirem perfurar a mesma.

O desenvolvimento de atividades de educação em saúde com relação a hábitos pessoais de higiene, particularmente o de lavar as mãos antes das refeições e o uso de calçados também devem ser considerados.

Outra possível medida profilática a ser adotada pelas escolas, consiste no preparo de solução contendo sal misturado com água (solução saturada de sal) e aspersão sobre a areia para eliminação de larvas de Ancylostoma sp., pelo menos uma vez por mês, visando inviabilizar a sobrevivência do parasita.

O controle da população de cães e gatos errantes também é uma medida necessária, visto que esses animais por não apresentarem tratamentos preventivos prévios, são os que apresentam as maiores taxas de prevalência a parasitoses e por terem, muitas vezes, acesso livre aos tanques de areia das escolas podem ser considerados potencias transmissores de parasitas a estas áreas.

\section{CONCLUSÃO}

Conclui-se que o ideal seria que os tanques de areia recebessem um cuidado especial realizando-se a análise parasitológica da areia anualmente por profissionais médicos veterinários, com a finalidade de pesquisar a prevalência de parasitas de importância em saúde pública e em medicina veterinária nos tanques de areia das escolas, de modo a permitir a toda comunidade acadêmica, dirigentes, professores, funcionários e alunos, conhecimento sobre as condições destes locais para que possam ser adotadas medidas visando garantir a saúde das crianças freqüentadoras destas áreas.

Espera-se com os dados obtidos neste trabalho, transformados em laudos e orientações, e disponibilizados para os dirigentes e professores de cada escola analisada, contribuir para a conscientização e redução da ocorrência de enfermidades parasitárias junto ao público infantil do município.

\section{REFERÊNCIAS}

ACHA, P. N.; SZYFRES, B. Zoonosis y enfermedades transmisibles communes al hombre y a los animales. 2 ed. Washington: Organización Panamericana de la Salud, 1989. 989 p.

ALDERETE, J. M. S. et al. Prevalence of Toxocara infection in school children from the Butantã region. Memórias do Instituto Oswaldo Cruz, São Paulo - SP, v. 98, n. 5, p. 593-597, Julho 2003.

ARAÚJO, F. R. et al. Contaminação de praças públicas de Campo Grande, Mato grosso do Sul, Brasil, por ovos de Toxocara e Ancylostoma em fezes de cães. Revista da Sociedade Brasileira de

Medicina Tropical, Campo Grande - MS, v. 32, n. 5, p. 581-583, Setembro-Outubro. 1999.

BRASIL, Ministério da Saúde. Doenças Infecciosas e Parasitárias - Guia de Bolso. 8 ed. Brasília: MS, 2010. 444p. 
BRITES NETO, J. Toxocaríase Humana. 1997. Disponível em: <

http://www.saudeanimal.com.br/artig176.htm>. Acesso em 11 de mar. 2010.

CAMARGO, L. B.; SANTOS, R. S.; MARQUES, M. P. A. Ocorrência de agentes causais de larva migrans em areias destinadas à recreação em escolas de ensino infantil em Espírito Santo do Pinhal SP, Brasil, 2003. Revista Ecossistema, Espírito Santo do Pinhal - SP, v. 28, n. 1,2, p.1-4, JaneiroDezembro 2003.

CARVALHO, E. A. A.; ROCHA, R. L. Toxocaríase: larva migrans visceral em crianças e adolescentes. Journal of Pediatrics, Porto Alegre - RS, v. 87, n. 2, Março-Abril 2011.

COSTA-CRUZ J.; NUNES R.; BUSO A. G. Presença de ovos de Toxocara spp. em praças públicas da cidade de Uberlândia, Minas Gerais, Brasil. Revista do Instituto de Medicina Tropical, São Paulo SP, v. 36, n. 1, p. 39-42, Janeiro-Fevereiro 1994.

CHIEFFI, P. P. et al. Toxocaríase. Instituto de Medicina Tropical de São Paulo, Faculdade de Ciências Médicas da Santa Casa de São Paulo, 2010. Disponível em:

<http://www.pasteur.saude.sp.gov.br/diadaraiva/pdf/Toxocariase_PEDRO_PAULO_CHIEFFI.pdf>. Acesso em 24 de abr. 2011.

DESPOMMIER, D. Toxocariasis: Clinical aspects, epidemiology, medical ecology and molecular aspects. Clinical Microbiology Reviews, New York, v. 16, n.2, p. 265-272, Abril 2003.

FORTES, E. Parasitologia Veterinária. 3 ed. São Paulo: Ícone, 1997. 685 p.

GUIMARÃES A. M. et al. Ovos de Toxocara sp. e larvas de Ancylostoma sp. em praça pública de Lavras, MG. Revista de Saúde Pública, Lavras - MG, v. 39, n. 2, p. 293-295, Agosto 2005.

HOFFMANN, R.P. Diagnóstico de Parasitismo Veterinário. Porto Alegre: Sulina, 1987. 156 p.

IBGE, Instituto Brasileiro de Geografia e Estatística, Censo Populacional 2010, p. 24, 2010.

Disponível em:

<http://www.ibge.gov.br/home/estatistica/populacao/censo2010/tabelas_pdf/total_populacao_sao_paul o.pdf>. Acesso em 24 de abr. 2011.

INSTITUTO DE MEDICINA TROPICAL DE SÃO PAULO. Toxocaríase. Disponível em: <http://www.pasteur.saude.sp.gov.br/diadaraiva/pdf/Toxocariase_PEDRO_PAULO_CHIEFFI.pdf $>$. Acesso em 24 de abr. 2011.

MORAES, R. G. Contribuição para o estudo do Strongyloides stercoralis e da estrongiloidose no Brasil. Revista do Serviço Especial de Saúde Pública, São Paulo - SP, v. 1, p. 507-624, Janeiro 1948.

NUNES, C. M. et al. Ocorrência de Larva Migrans na areia de área de lazer das escolas municipais de ensino fundamental, Araçatuba, SP, Brasil. Revista da Saúde Pública, São Paulo - SP, v. 34, n. 6, p. 656-658, Dezembro 2000.

PARASIDIÁRIO. Ancilostomose. Disponível em: <http://parasidiario.blogspot.com/>. Acesso em 24 de abr. 2011.

POLICLÍNICA VETERINÁRIA DE COTIA. Zoonoses. Disponível em: < http://www.policlinicaveterinaria.com.br/artigos.asp?xcod=31>. Acesso em 24 de abr. 2011.

REY, L. Parasitologia. 3 ed. Rio de Janeiro: Guanabara Koogan, 2001. 860 p. 
ROCHA, J. R. et al. A. Incidência do parasita Ancylostoma sp. no município de Garça - SP. Revista Científica Eletrônica de Medicina Veterinária, Garça - SP, v. 4, n.10. Janeiro 2008.

SCHANTZ, P. M. Toxocara larva migrans now. American Journal of Tropical Medicine and Hygiene, Atlanta, v. 41, n.3, p. 21-34, 1989.

SOTOMAIOR, C. S. et al.. Parasitoses gastrintestinais dos ovinos e caprinos : alternativas de controle. Instituto Paranaense de Assistência Técnica e Extensão Rural - EMATER. Curitiba - PR, v. 9, n. 80, p. 17-18, 2009.

UCHÔA, C. M. ${ }^{a}$ et al.. Parasitoses intestinais: prevalências em creches comunitárias da cidade de Niterói. Revista do Instituto Adolfo Lutz, Rio de Janeiro - RJ, v. 60, n. 2, p. 97-101, Abril-Junho 2001.

URQHART, G. M.; ARMOUR, J.; DUNCAN, J. L. Parasitologia Veterinária. 2 ed. Rio de Janeiro: Guanabara Koogan,1996. 273 p.

YAMASAKI H. et al.. Development of a highly specific recombinant Toxocara canis second-stage larva excretory-secretory antigen for immunodiagnosis of human toxocariasis. Journal of Clinical Microbiology, Malásia, v. 38, n. 4, p. 1409-1413, Abril 2000. 
